\title{
Lateral variations along the Main Central Thrust in the central Nepal Himalayas: The evidence from chemical maps of garnet
}

\author{
Haruka Yamaguchi† ${ }^{*}$ and Kazunori Aritał \\ † Institute for Frontier Research on Earth Evolution (IFREE), Japan Agency of Marine Science and Technology (JAMSTEC), \\ Showa-cho 3173-25, Kanazawa-ku, Yokohama, 236-0001, JAPAN \\ $\ddagger$ Division of Earth and Planetary Sciences, Graduate school of Science, Hokkaido University, Kita-10 Nishi-8, Sapporo, \\ 060-0810, JAPAN \\ *To whom correspondence should be addressed.E-mail: harukay@jamstec.go.jp
}

Chemical maps of garnet are the key to understand the tectonometamorphic evolution of the metamorphic rocks. They provide useful information on element distribution, diffusion, and mechanical truncation of crystal. In the Himalayas, studies on ultra-high pressure rocks denudated along the Main Central Thrust (MCT) revealed the great displacement along this intracontinental shear zone. Pêcher (1989) suggested the difference in thickness of hangingwall as a result of large erosion along the thrust, and Macfarlane (1993) discussed the various thermal structures within the hangingwall. However, lateral variations in footwall have been poorly investigated although inverted thermal gradient has been often discussed. In order to clarify the variation of tectonometamophic events along the MCT, garnet crystals within pelitic rocks were investigated in detail.

In the central Nepal Himalayas, Annapurna area and Kathmandu nappe are suitable to study these variations. Estimated metamorphic temperatures just above the MCT are different in two areas: $600-700^{\circ} \mathrm{C}$ in Annapurna area (Kaneko et al. 1995) and $550-600{ }^{\circ} \mathrm{C}$ in Kathmandu nappe (Johnson et al. 2001). These variations are interpreted as different positions within hangingwall; Kathmandu nappe corresponds to frontal zone whereas Annapurna area to root zone.

Microstructures of garnet in the Annapurna area and Kathmandu nappe are almost the same, characterized by tripartite growth: 1) core with spiral inclusion, 2) mantle with/ without non-arranged inclusion which is asymmetrically truncated at rim and 3) re-overgrown rim. On the other hand, chemical zonings of garnet are slightly different in two areas. In the both areas, constant decrease of Mn from center to mantle and high Mn rim is observed, but Mg zoning at rim show opposite pattern, decrease in Annapurna area whereas increase in Kathmandu nappe.

The exact P-T paths have been deduced by Gibbs method, inverse differential calculation using garnet growth zoning and mineral assemblages in the rock. Results show clockwise P-T path from center to mantle part, which is adiabatic compression ( $\mathrm{dP}$ $\left.=0.2-0.3 \mathrm{GPa}, \mathrm{dT}=30^{\circ} \mathrm{C}\right)$ followed by heating $\left(\mathrm{dT}=30^{\circ} \mathrm{C}\right) . \mathrm{P}-\mathrm{T}$ condition at rim show different path in each area, decompression cooling $\left(\mathrm{dP}=0.2 \mathrm{GPa}, \mathrm{dT}=30^{\circ} \mathrm{C}\right)$ in the Annapurna area and decompression heating $\left(\mathrm{dP}=0.3 \mathrm{GPa}, \mathrm{dT}=50{ }^{\circ} \mathrm{C}\right)$ in the Kathmandu nappe.

Comprehensively, two shearing evidences of spiral trail at core and asymmetrical truncation between mantle and rim may be referred to as underthrusting and exhumation, for their adiabatic compression and decompression paths. Evidences also show the cooling at root zone (Annapurna area) and heating at frontal nappe (Kathmandu nappe) after the exhumation, which suggest that rapid denudation occurred at hangingwall of root zone whereas heating from hangingwall continued at the front zone.

\section{References}

Pêcher A. 1989. The metamorphism in the central Himalaya. JMetamorph Geology 7(1): 31-41

Macfarlane AM. 1993. Chronology of tectonic events in the crystalline core of the Himalaya, Langtang National Park, central Nepal. Tectonics 12(4): 1004-25

Kaneko, Y. 1995. Thermal structure in the Annapurna region, central Nepal Himalaya: implication for the inverted metamophism. J Min and Econ Geol 90: 143-154

Johnson MRW, GJH Oliver, RR Parrish and SP Johnson. 2001. Synthrusting metamorphism, cooling, and erosion of the Himalayan Kathmandu Complex, Nepal. Tectonics, 20(3): p. 394-415 